DOI: $10.1515 /$ hssr -2015-0014

\title{
Intertheoricity: Plasticity, Elasticity and Hybridity of Theories. \\ Part II: Semiotics of Transferogenesis
}

Astrid Guillaume *

Université Paris Sorbonne, France

\begin{abstract}
Theories are processes modelled by thought. When they evolve in time, they are transformed and become new theories. They may cross from one academic discipline to another, then open up to new areas of human knowledge, mixing together the humanities, art, science and even spirituality. The way they are modelled reveals their plasticity and their elasticity is tested in their potential for transfer from one field to another, while the different contacts they make and mergers they undergo generate a certain hybridity. Plasticity, elasticity and hybridity are the triad which makes the transfer of theories possible.
\end{abstract}

Keywords

Intertheoricity, Plasticiy, Hybridity, Linguistics, Transdisciplinarity.

EA4509 Sens, Texte, Informatique, Histoire, Paris-Sorbonne University, 1, Victor Cousin Str., 75005 Paris, France; astrid.guillaume@live.fr (Article translated into English by Sorina Chiper, "Alexandru Ioan Cuza” University of Iasi). 
HSS, vol. IV, no. 2 (2015): 59-77

« Rien ne se perd, rien ne se crée, tout se transforme 》

Nothing is lost, nothing is created, everything is transformed)

Antoine Laurent de Lavoisier

\section{Example of intertheoricity: transferogenesis}

François Rastier, in his studies of the cultural object, came up with the following definition:

"If buman action transforms bodies into cultural objects and into waste, let us point out that this indefinite process undergoes stages of destructive creation, which dismantle objects so as to turn them into the material for new objects, even of pure destruction, as we can notice every day. (...) Thus, for instance, a cultural object, as soon as it ceases to be interpreted at the heart of chains of action and of a social practice, can resemble a simple body, even some waste". "

This is an important aspect for our argument because theories are cultural objects just like any others. As such, they are transferred in time. In order to follow them, a praxeological typology of their diachronic trajectory is illuminating.

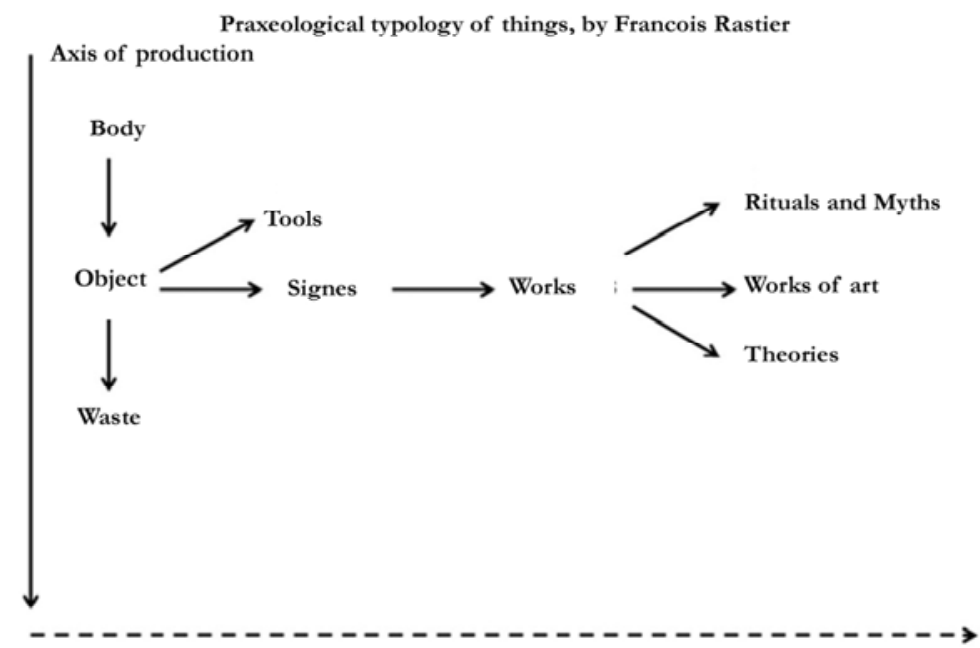

Axis of creation and interpretation

Figure 4: François Rastier's praxeological typology ${ }^{2}$ 
If we take the example of the Middle Ages as a cultural object, it falls under a diachronic curve, as follows:

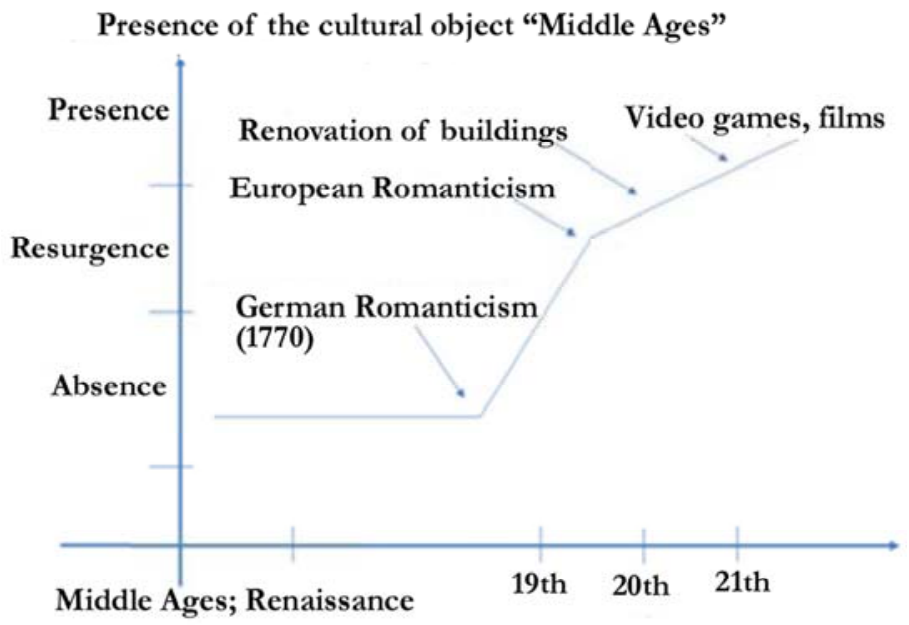

Figure 5: Diachronic curve of the cultural object "Middle Ages"

Any cultural object has, potentially, its diachronic curve; this makes it possible to identify its resurgence and to establish whether it develops into a recycled object or toxic waste on a short, middle and long term, on the basis of a hybrid corpus, bringing together the traces of the object at the core of a society and of an age. To analyse it implies to know the (ancient and contemporary) target languages and civilizations in which the object will reappear, and the (ancient and contemporary) source languages and civilizations from where it emerged.

If we preserve the example of the Middle Ages, let us consider a praxeological typology of recycling, as follows: 


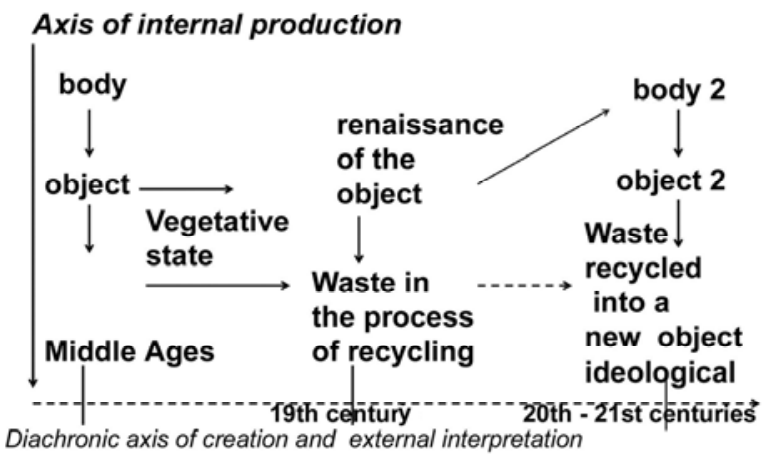

Figure 6: Praxeological typology of the cultural object Middle Ages ${ }^{3}$

Or on the contrary, a typology which can make a cultural object evolve towards toxic cultural waste when it is used again for ideological purposes that are historically de-contextualised, would be like the one below:

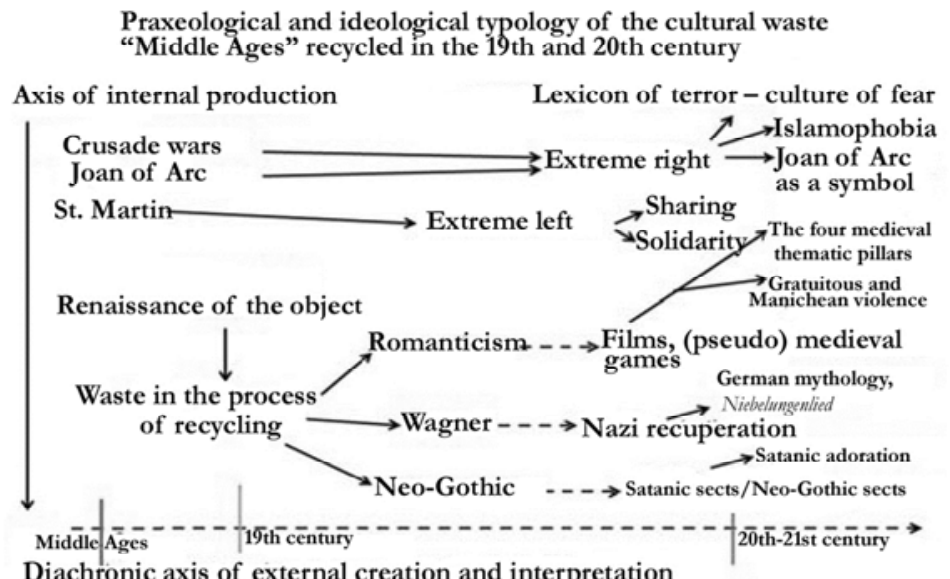

Figure 7: Praxeological typology of the cultural waste "Middle Ages"4 
The same holds true for theories; some of them will evolve towards positive constructions for humanity (discovery of vaccines, technological inventions for more comfort for humans), others towards the destruction of humanity (passéisms, Nazi theses that re-emerge via neoNazi theses).

\section{Consequences and publics concerned by the ideological recovery of the} recycled cultural waste "Middle Ages" in the $21^{\text {st }}$ century

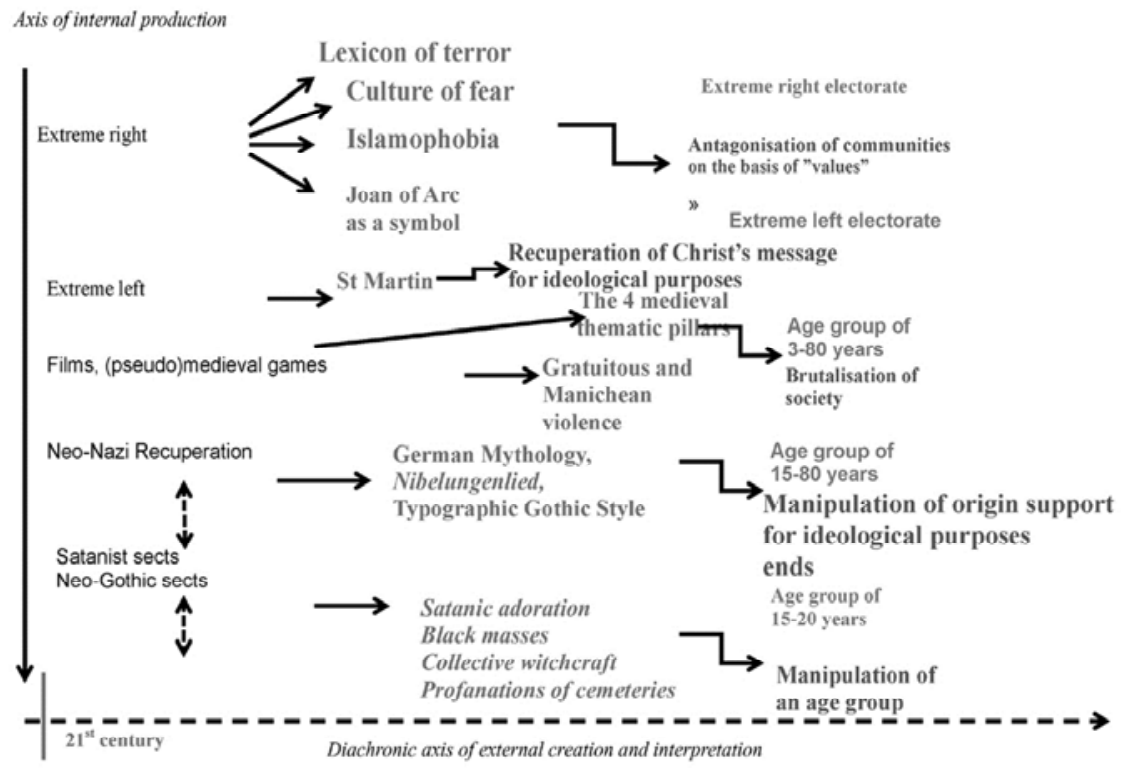

Figure 8: The "Middle-Ages" as cultural waste recycled nowadays 5

The latter remarks, which evoke notions of cultural objects versus cultural toxic waste or positive evolution versus negative evolution, introduce the essential notion of ethics in the process of intertheoricity, to be considered in all scientific areas in connection with the sciences of culture, of man and of nature, something which neither religious thoughts nor the currently flourishing ethics committees could reject. We have specified somewhere else ${ }^{6}$ how to evaluate the good and the bad via a golden rule 7 . The most popular golden rule is Do not do unto others what you don't want others to do unto you: we can find this rule in the writings of all sages and in all beliefs of the world, under different forms and languages 
but with a very similar meaning, a golden rule which is then susceptible of having been received and thus known by most people.

If we go back to Greimas' classical sequential equations, we have:

\section{- Subject versus Object}

$\rightarrow$ Classical disjunctive transformation: $\mathrm{F}(\mathrm{S} 1)=>[(\mathrm{S} 2 / \mathrm{O})->(\mathrm{S} 2$

$\checkmark \mathrm{O})]$

$\rightarrow$ Classical conjunctive transformation: $\mathrm{F}(\mathrm{S} 1)=>[(\mathrm{S} 2 \backslash / \mathrm{O})->(\mathrm{S} 2$

$\bigwedge \mathrm{O})]$

The application of this golden rule to establish universal ethical values cannot function starting from Greimas' sequential equations, because in the present case we must banish the You-object to replace it systematically with an $I$-subject, where I = You, namely:

\section{- Subject $=$ Secondary Subject}

$\rightarrow$ Conjunctive transformation of universal ethics:

$$
\mathrm{F}(\mathrm{S} 1)=>[(\mathrm{S} 2 \backslash / \mathrm{O})->(\mathrm{S} 1 / \mathrm{S} 2)]
$$

Banishing the You-object, and therefore the object, to replace it systematically by a second $I$ - subject, a second subject having an objectsubject function leads directly to:

$\rightarrow$ Consider You as if it were $I$ or consider the Object as if it were Subject.

Or, do not do onto others what you do not like others to do unto you, that is think of the other as if he or she were yourself, think of You as a living $I$ subject to be respected as yourself no matter what its form and condition might be. Consider alterity as $I$.

For Greimas, the object has to equip itself "with a will to be so that the value of the subject in the semiotic meaning of the term could change into value for the subject's.

The semiotics of ethical values is first a "semiotics of the will to be," which in conjunction will turn into a semiotics of being-being. A transfer 
is therefore operated here, also towards a final in esse. But the $I$, in a world where the antagonist (sphere $t_{\mathrm{n}}$ superior in value, cf. above) is selfishness, individualism or obscurantism, is transferred to You with great difficulty, and the You does not come to see itself as an $I$ for reasons of radically different cultures and traditions, when the latter are not ancestrally antagonist. To this we can add that since Pascal's time, we have come to the idea that " $M y$ self [and therefore the $I$ ] is lothable", which we could admit especially when it is ego-centred. In this case, it excludes or does not respect the object in its dignity, that is, here, the other (human, animal, nature). But if this $I$ manages to be projected depending on the secondary subject, then the $I$ becomes the pinnacle of ethics (being-being) by transforming the object into the subject (S2), to be respected as one's self (S1). This should be the goal of any human being who respects himself or herself, and therefore respects the Other who is You! Hence:

\section{- First subject $=$ Second subject}

$\rightarrow$ Conjunctive transformation of universal ethics:

$\mathrm{F}(\mathrm{S} 1)=>[(\mathrm{S} 1 \backslash / \mathrm{O})->(\mathrm{S} 1 / \mathrm{S} 2)]$

Also, let us return to an issue already evoked, that of Last Judgments, which were very much present in the past, from Middle Ages up to mid$20^{\text {th }}$ century, for the pedagogical aspect of the moral which they conveyed. They are still implicitly present nowadays in our lay societies in notions of ethics or deontology?

We add to our process the notion of agonist (sphere $+n$ superior in value) and of antagonist (sphere $-\mathrm{n}$ inferior in value) which permits this binary tension, deliberately Manichean, between the good and the evil, between the cultural object and toxic cultural waste, in what we have called somewhere else the semiotic harmony of tensions.

In terms of the $+n /-n$ zones, we have passed from the dictatorship of the medieval divine $\mathrm{He}$ (Figure 4) to the solidarity between I and You; in this case the $\mathrm{He}$ becomes humanity: it is no longer the transcendence but the universality of Human and Animal Rights (an inheritance of universal wisdom, be it religious or not) which thus becomes a horizon that allows to put an end to the relativity of values drawing on customs (crimes in 
the name of honour, archaic traditions, differences of treatment between sexes, etc.).

In philosophy, "The world is a harmony of tensions"10; the same holds true for physics, ethics, linguistics, as well as semiotics. These tensions and this harmony are represented here by the triangle of the triad with its three implicit notions and a spatio-temporality borrowed from pictorial representations of Last Judgments:

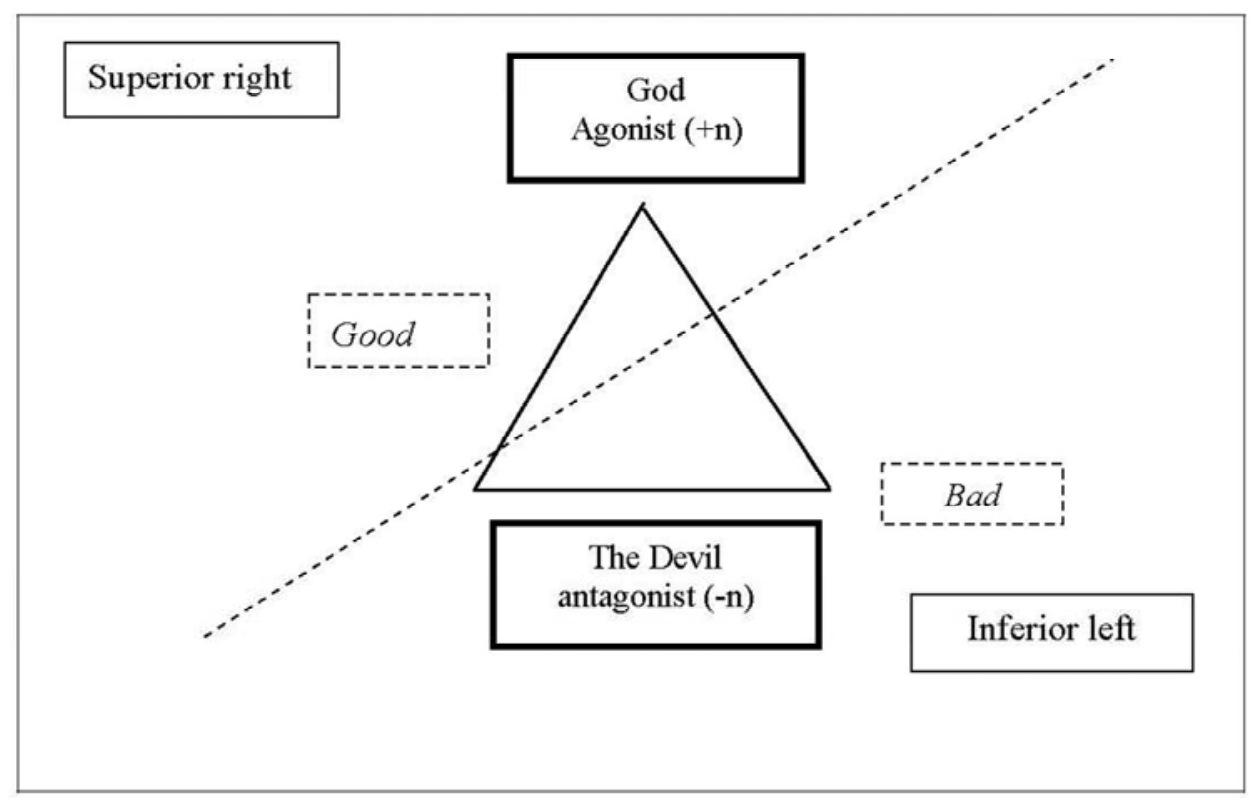

Figure 9: Semiotic harmony of religious tensions from the Middle Ages up to nowadays

Placing this modelling in a contemporary and lay context, with concrete examples in connection with the transfer, leads to this new figure: 


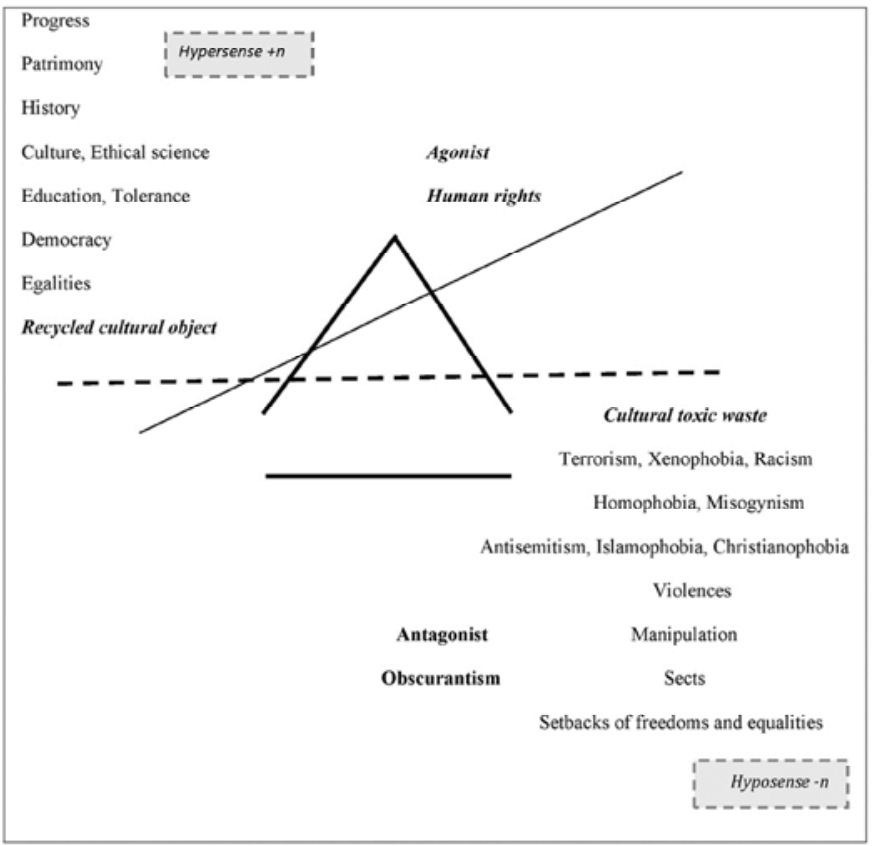

Figure 10: Semiotic harmony of tensions emerging from sense transferability

The notions of hyper-sense and hypo-sense (positive or negative semantic use in connection with three notions reunited by a triad) require semantic and lexicological studies in synchrony, and etymological studies in diachrony based on a civilisational and lexical corpus. We have showed in another article that Peirce's theories, his triads and his tritriangular thinking could well be transferred to the thinking of the Middle Ages, a Christian period par excellence, because Peirce was highly influenced by Duns Scot's philosophy. We have reused the triangle to place it as the heart of the ethical process, in connection with a binary tension that was dear to Gustave Guillaume in his chronogenesis. We have seen somewhere else that in order to study a cultural object in time - in the Middle Ages, as it is our case here - the theories of Ferdinand de Saussure (diachrony-synchrony) and of François Rastier (cultural object and sciences of culture) could open numerous paths to be set in contact with the cultures, languages, political systems and beliefs, to define the recycling, in time, of the cultural object in diachrony and in synchrony ${ }^{11}$. 
The semiotic harmony of tensions allows one to follow the evolution of cultural objects from the past and to define their future, exploitation, and re-semantization within contemporary society. The agonist in the contemporary, lay context is no longer God but the observance of human rights; the antagonist is no longer the devil but obscurantism in all its forms, the return to archaic practices or the desire to return to values of the past, an approach that is fundamentally impossible, therefore one of the most likely to induce anxiety.

Transferogenesis falls within the scope of these ethical and intertheorist concerns; it starts in diachrony and finishes in synchrony; it is concerned with both linguistic and civilisational cultural objects, and is part of a semiotics of cultures intended to study the sciences of culture in context.

Transferogenesis is made of an actantial synergy which comprises:

1- A triad representing internal geometry

2- The tri-triangular dynamics

3- The harmony of semiotic tensions

It features a praxeological typology and a diachronic curve which allows one to follow the cultural object in time and its uses as a cultural object or as toxic waste.

Finally, the transfer meets three requirements which are present in the Buddhist philosophy and which are three elements called here "the three Is": Impersonality, Impermanence, and Insatisfaction.

The sense, the sign, words, cultures, as well as the various theories of the above mentioned researchers, respond to the three characteristic features that Buddhists consider to be the three stages of existence, the principle of life and death of everything that exists in the universe (be it animal, vegetal or mineral, and also pertaining to the cultural object), namely:
1-Impersonality: everything is interdependent.
2-Impermanence: everything is changing, nothing is permanent ${ }^{13}$.
3-Insatisfaction: nothing is satisfactory for good ${ }^{14}$. 
- 1 - The impersonality of the cultural object: explicit or implicit, it has an internal tri-triangular geometry which reveals itself through a triangular action-based synergy and a harmony of tensions. It is interdependent on three values.

$\rightarrow$ in posse.

- 2- The impermanence of this trichotomic structure: it is evolutive via an ethical programme which creates a binary tension between the agonist and the antagonist, which generates a dynamics, that allows the transition of the transfer to be operated.

$\rightarrow$ in fieri.

- 3- Insatisfaction. The intercultural and intertemporal transferability of the cultural object is done in a Bergsonian-like cyclic time, a non-linear time made of disappearance and reappearance under various and varied forms, temporalities and spaces which generate a transformation of the initial object, a transformation which is real but always final.

$\rightarrow$ in esse.

These different processes and stages show that the cultural object (word, expression, concept, language, text, translation, sign, symbol, theory, etc.) is transformed in diachrony; it can disappear and reappear several centuries later. This renaissance is therefore inscribed in the recycling process of the cultural object which, in the best-case scenario, turns it into a recycled cultural object and in the worst case scenario, into toxic waste, re-connoted, reused and, in this case, potentially dangerous. Irrespective of the outcome of the recycling process, the cultural object observes the rule of the three Is.

Words, signs and cultures, as cultural objects, are all transferable in time, and thus subject to this transfer process; they could be more or less integrated and visible in society, more or less diffuse via the new means of communication which would ensure them a long or short process of becoming. The cultural object emerges within a determined age and in a 
precise context; it adapts to it and develops in it depending on the political, religious and cultural environment. It is used, more or less well and for a longer or shorter time, depending on its visibility within society: if it is de-contextualised and re-integrated in another age, it is no longer the same cultural object as in its initial environment. The geographic or temporal movement of any biological organism impacts its metabolism, in a certain way; the same holds true for the cultural object.

As we cannot project ourselves into the future, the study of the transferability of meaning looks strongly into the past, in a long, medium and short term perspective, and in the most immediate present: it reunites again, as Saussure wished it, diachrony and synchrony on the same level of equality.

If we were to quote Saussure just once, we would choose this essential thought for our approach:

The infidelity of the past is just relative. This is why the principle of alteration is grounded on the principle of continuity ${ }^{15}$.

The core of the transferability of meaning, or of its transferogenesis, is somehow summarised by these two sentences. Everything that needs to be precisely defined for each case can be found there, namely the terms of relativity, alteration and continuity, which are the triad that represents the internal geometry of transferability.

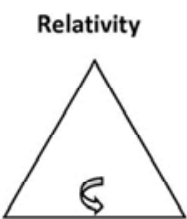

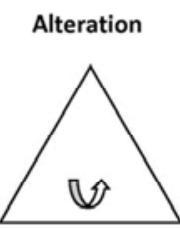

Continuity Alteration
Continuity

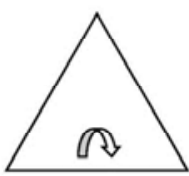

Relativity

Alteration

Continuity Relativity

Figure 11: Internal geometry of transferability

This internal geometry generates, in action, the following tritriangular dynamics: 


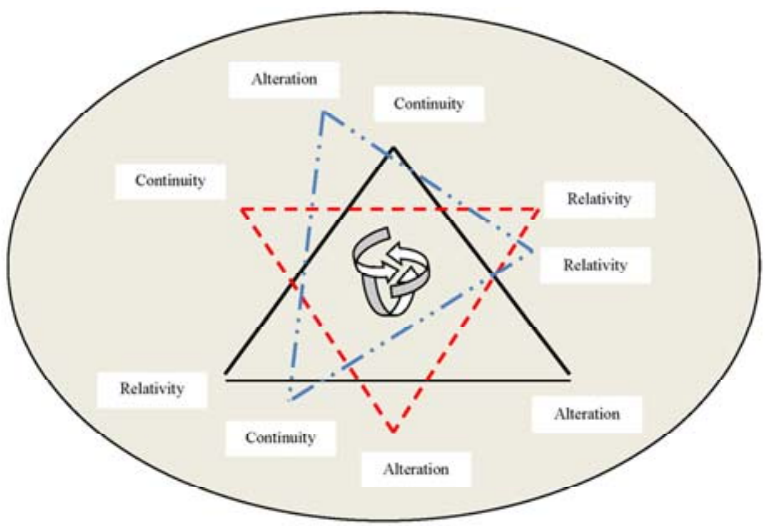

Figure 12: Tri-triangulary dynamics of transferogenesis

The semiotic harmony of the tensions of transferability (Figure 10) defines the toxicity (or not) of elements of the past (cultural objects) transferred nowadays. It will also depend on the ethical programme that can be attributed to them (or not):

ethics, detached from its religious foundations, currently pertains to culture, and it falls upon a semiotics of cultures to study it, without claiming to redefine its tasks ${ }^{16}$ : it thus becomes a theory of the law and of norms. ${ }^{17}$

The semiotic harmony of tensions is triangular and ternary; it is cut in its centre, like a final Last Judgment, to separate the hyper-sense from the hypo-sense. It allows one to apprehend a dynamics connected to a third element: these three reunited elements generate movement, and therefore the dynamics of transfer. But to get out immediately from the binary/ternary conflict, it seems here that the ternary serves better than ever the binary, and the binary the ternary, as when they operate together, the binary allows the configuration of the tension (here, between agonist and antagonist) of the triadic dynamics, and the ternary allows the configuration of movement ( 2 binary elements +3 ternary elements $=5$ elements $^{18}$ ).

At the level of theoretical modelling, we borrow from Peirce his mode of thinking with his trinitary system, which adapts itself to the JudeoChristian thought and to the cultures from the Middle Ages up to 
nowadays, and can evolve towards a more contemporary lay ternary system; from Saussure, we borrow his dualities which create here the underlying tension (agonist/antagonist), and from Gustave Guillaume his genesis (in posse, in fieri, in esse).

\section{Conclusion}

A ternary system, made up of a triad against the background of a binary tension, seems better adapted to analyses on the transferability of meaning. Otherwise, the triangularity that Kandinsky was so fond of, offers the possibility to escape from a too Manichean binary system, by not allowing complex dynamics to be revealed.

Finally, to understand and to know how to identify immediately the moment when a cultural object develops into a recycled object or into toxic waste, means to be able to understand different types of manipulations, be they on the cultural, media, advertising, ideological or political level.

This approach would have shown that irrespective of the cultural support and implicit and explicit contents, and irrespective of the age, using concrete facts and cultural objects by subjecting them to abstraction allows one to conceptualise the comings and goings of ideas in time from the past to the present, as well as from the present towards the past. This tends to show that the cultural object has certain longevity in time, i.e. it moves in time, and that the time of the sciences of culture seems to be Bergsonian or Proustian (spiral, non-linear time).

These researches also prove that in the programme of a diachronic semiotics of cultures, any cultural object can, potentially, prove itself in the transfer, in which case it is plastic, elastic and hybrid, as the change of context and age generates a hybridity connected to adaptation in the new context.

The issue will then have to be defined systematically if the cultural object is transferred in time or not, and if yes why, how, over what lapse of time and in which context. The sciences of culture function in diachrony, just like the semiotics of cultures, because the notion of culture is intimately linked to those of time, development, evolution, tradition(s), continuity, promiscuity and rupture, permanence and impermanence. Diachrony proves to be one of the main pillars of transferogenesis. 
This is why the transferability of cultural and linguistic meaning approached here is finally the virtual and actual diachronic transfer of words and signs, which are the traces of cultures which acquire another meaning in time. Nowadays more than 7,000 disciplines exist side by side, quite often without ever meeting each other, which makes it difficult to deeply analyse a series of topics in movement. If scientific disciplines were strongly isolated during the second half of the $20^{\text {th }}$ century, they seem to be dis-isolating themselves increasingly more in the beginning of the $21^{\text {st }}$ century so as to proceed towards more than interdisciplinarity, pluridisciplinarity and transdisciplinarity. This reversal of isolation is a happy, desirable and welcome event. It must be pursued and from now on, it must open itself to the intertheoricity which is still too little practiced outside of the arts and sciences. ${ }^{19}$

\section{Brief glossary of transferogenesis}

Agonist: it allows, together with the antagonist, to create the moral or ethical tension (depending on the studied period) of the cultural object in transfer. In the Middle Ages, a theocratic period, the agonist is God versus the Devil, the Good versus the Evil. Nowadays, in democracy, the agonist is Humanism versus Obscurantism, human and animal rights versus the exploitation of man and of animals, etc. The agonist represents the values of a high order, the moral or the ethics of a period or of a culture.

Antagonist: it is the opposite of the agonist, an element which creates tension leading to equilibrium. The antagonist represents the values of the lower order, the negative within a deontology or an ethics defined by passing through a golden rule: "do not do onto the other what You do not want to be done to you".

Diachronical curve of the cultural object. The curve of the cultural object allows to check its presence, its absence or resurgence in time. In order for it to be achieved, it requires a study of the object in diachrony, in context, i.e. in contrastivity. (Cf. curve of the cultural object Middle-Ages which passes through the $19^{\text {th }}$ century and the $20^{\text {th }}-21^{\text {st }}$ centuries by changing its ideology). 
HSS, vol. IV, no. 2 (2015): 59-77

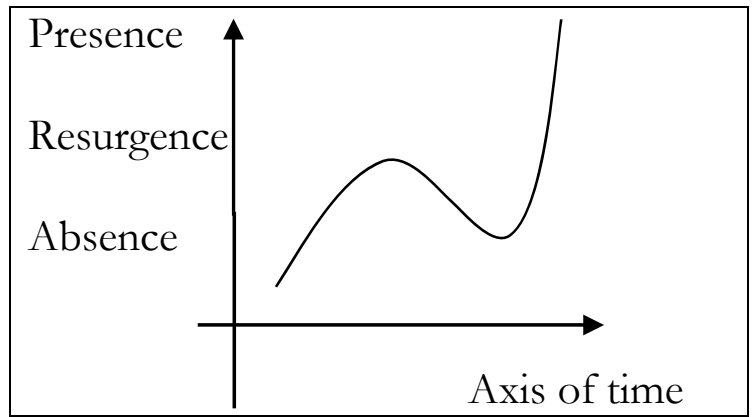

Tri-triangular dynamics: It represents the entire process in action on an overview axis of the transfer process. It is inscribed on a syntagmatic axis while the internal geometry is inscribed on a paradigmatic axis.

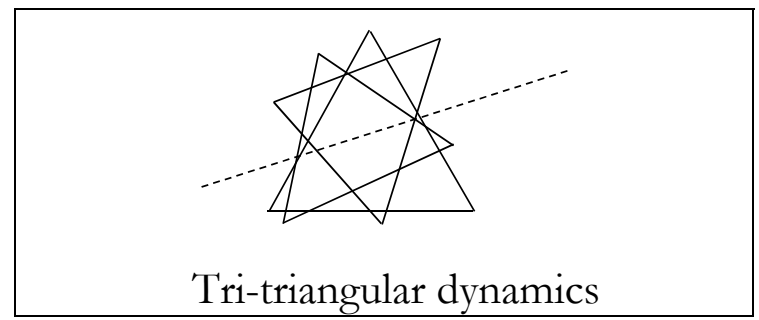

Internal geometry: It reunites a triad of three notions that constitute the cultural object studied at different moments of the action. Sometimes one of the notions is at the heart of the described process; in this case, it lies at the peak of the triangle, and the other two constitute its basis. In the process, each notion is located at a given moment at the peak of the triangle on a paradigmatic axis. On the syntagmatic axis, we find again the tri-triangular dynamics which represents simultaneity.

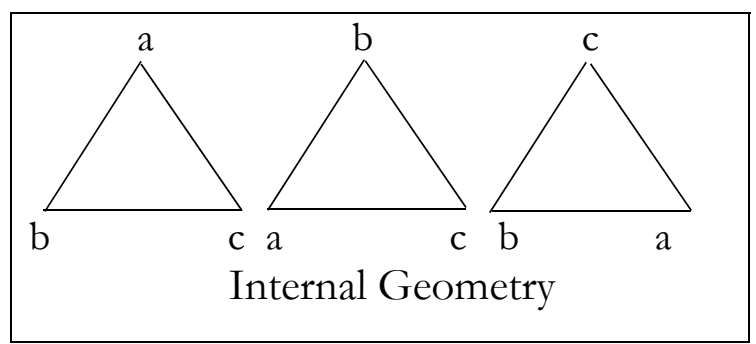


Semiotic barmony of tensions: modelling that represents the fund of the agonist and the antagonist's semiotic tension.

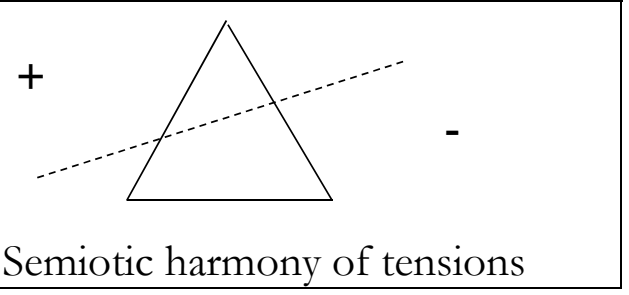

Hyper meaning: semantic sphere and field of the agonist.

Hypo meaning: semantic sphere and field of the antagonist.

Impermanence: in a transfer process, nothing is permanent by definition.

Impersonality: in a process of transfer, everything is interdependent, the elements of the past as well as those of the present. Impermanence is one of the three indispensable elements, together with impersonality and insatisfaction, for a transfer to be operated.

Insatisfaction: in a process of transfer, insatisfaction will generate the transfer because nothing is definitely satisfactory. It is part of the triad impermanence, impersonality, insatisfaction.

Intertheoricity: process of creation of theories which brings together elements of other theories. Intertheoricity is for theories what intermediality is for the media, intertextuality for literary texts, interartiality for arts. It is an unavoidable element of transferogenesis.

Actantial synergy: summarises the three stages of the transfer process which are internal geometry, three-triangular dynamics and semiotic harmony of tensions.

Transferogenesis: summarises the internal transfer process of any cultural object; it is the genesis of the transfer, and it can be captured in the following three notions: 1-impersonality: everything is interdependent, 2 impermanence: everything is changing, nothing is permanent. 3- Insatisfaction: nothing is satisfactory for good. In order for it to take effect, the transfer will feature a triad, which can be found in the internal geometry, which is translated into dynamics in the tri-triangular dynamics, and into tension in the semiotic harmony of tensions. These three stages are called actantial synergy. 
Triad: It brings together three notions under the shape of a triangle which represents the core of the cultural object in transfer.

1 François Rastier, «Objets culturels et performances sémiotiques, l'objectivation critique dans les sciences de la culture », p.21. Our emphasis.

${ }^{2}$ Ibidem, p. 20.

${ }^{3}$ Astrid G. «Pour une sémiotique diachronique des cultures : le "Moyen-Âge" aujourd'hui», in Textes, Documents, CEuvre: Perspectives sémiotiques, ed. Driss Ablali, Sémir Badir, Dominique Ducard, Cerisy-la-Salle- juillet 2012, Presses universitaires de Rennes, 2014, 381-406.

${ }^{4}$ Ibidem.

${ }^{5}$ Ibidem.

${ }^{6}$ Astrid G., « De la morale médiévale à l'éthique contemporaine: sémiotique de la valeur d'hier et d'aujourd'hui », in Valeurs. Aux Fondements de la sémiotique, ed. Amir Biglari, L'Harmattan, 2015.

${ }^{7}$ Ibidem

${ }^{8}$ Algirdas Julien Greimas, «Un problème de sémiotique narrative : les objets de valeur », in Langages, Volume 8, Year 31, 1973, 20.

${ }^{9}$ Ibidem.

${ }^{10}$ Heraclitus of Epheseus.

${ }^{11}$ Astrid G. "Pour une sémiotique diachronique des cultures : le "Moyen-Âge" aujourd'hui », in Textes, Documents, CEuvre: Perspectives sémiotiques, ed. Driss Ablali, Sémir Badir, Dominique Ducard, Cerisy-la-Salle, July 2012, Presses universitaires de Rennes, 2014, 381-406.

${ }^{12}$ Confirmed, for instance, for the symbol in Lévi-Strauss' works.

${ }^{13}$ The very principle of transfer and dynamics.

${ }^{14}$ Any theory is brought to be adapted or revised, its meaning is brought to lead to mutations.

${ }^{15}$ Cours de Linguistique Générale, p. 109. Our emphasis.

${ }^{16}$ Cf. Schleiermacher, Brouillon zur Ethik, on "the ethical essence of the idea of culture" in Berner, 1995, p. 241.

${ }^{17}$ François Rastier, «L'Action et le sens... », p. 210.

http://www.revue-texto.net/Inedits/Rastier/Rastier_Action.html\#4.2. « $\grave{A}$ l'époque contemporaine, la laïcisation de la connaissance a remplacé l'éthique par la psychologie ou par la philosophie de l'esprit, disciplines dominées par la problématique de la représentation et où l'action tient de fait peu de place. Parallèlement, les sciences humaines se trouvent en charge du social, dont l'éthique formulait la règle, ou en rivalité avec une théorie des idéologies. Même si les sciences humaines se sont séparées de la philosophie en refusant le 
problème du bien, il revient sans cesse sous diverses formes obliques, plus ou moins euphémiques, comme la prétention à la validité "/Nowadays, the laicization of knowledge has replaced ethics by psychology or by the philosophy of the spirit, disciplines dominated by the issues raised by representation and in which action tends to hold little room. In parallel, buman sciences are in charge with the social aspects, whose rules are formulated by ethics, or in rivaly with a theory of ideologies. Even though human sciences have broken off from philosophy by refusing the problem of the good, it ceaselessly returns under various oblique forms, more or less euphemic, such as the pretension to validity".

${ }^{18}$ In all cosmogonies of the world we encounter five elements that any genesis originates from.

${ }^{19}$ We thank François Rastier for his reading and suggestions.

\section{Biographical note}

Astrid Guillaume, HDR, is an assistant professor at the Paris Sorbonne University (Paris IV), Director of the collection Traditions et Croyances aux Presses de l'Université Paris-Sorbonne, member of the International Center for Transdisciplinary Research (CIRET), member of the scientific committee of the Fondation Droit Animal, Ethique et Sciences (LFDA) and founder vicepresident of the European Observatory on Plurilinguism (EOP). She authored mainly Plurilinguisme, Interculturalité et Emploi : Défis pour l'Europe, L'Harmattan, 2009 ; "Pour une sémiotique diachronique des cultures : le "Moyen-Âge" aujourd'hui ", in Textes, Documents, OEuvre: Perspectives sémiotiques (Autour de François Rastier), Presses universitaires de Rennes, 2012. 